\title{
Contemporary Modalities in the Prevention of Contrast-Induced Acute Kidney Injury
}

\author{
Panagiotis Theofilis* and Aikaterini Vordoni \\ Department of Nephrology, General Hospital of Nikaia "Agios Panteleimon", Athens, Greece
}

*Corresponding author: Panagiotis Theofilis, Nephrology Department, General Hospital of Nikaia "Agios Panteleimon"Dimitri Mantouvalou 3, Nikaia, Greece

\section{ARTICLE INFO}

Received: 业 May 12, 2021

Published: 幽 May 19, 2021

Citation: Panagiotis Theofilis, Aikaterini Vordoni. Contemporary Modalities in the Prevention of Contrast-Induced Acute Kidney Injury. Biomed J Sci \& Tech Res 35(5)2021. BJSTR. MS.ID.005771.

\begin{abstract}
Contrast-induced acute kidney injury (CI-AKI) is the third leading cause of acute kidney injury deriving from the intravascular administration of contrast media in diagnostic and therapeutic procedures and leading to longer in-hospital stay and increased short and long-term mortality. Its pathophysiology, although not well-established, revolves around medullary hypoxia paired with the direct toxicity of the substance to the kidney. Critically ill patients, as well as those with pre-existing renal disease and cardiovascular comorbidities, are more susceptible to CI-AKI. Despite the continuous research on the field of CI-AKI prevention, clinical practice is based mostly on periprocedural hydration. In this review, all the investigated methods of prevention are being presented, with the potency of RenalGuard and contrast-removal systems being stressed as the method of choice for CI-AKI prevention in high-risk individuals.
\end{abstract}

Keywords: Contrast-Induced Acute Kidney Injury; Contrast Media; Prevention

\section{Introduction}

Contrast media (CM), intravascularly administered in radiodiagnostics to enhance vascular visibility, have as complication the occurrence of acute kidney injury, beginning soon after their administration. This clinical entity is known as contrast-induced acute kidney injury (CI-AKI) and is the third leading cause of acute kidney injury, after defect of renal perfusion and nephrotoxic drugs administration [1]. CI-AKI is associated with elevation of serum creatinine after exclusion of alternative causes of renal impairment, within 48-72 hours after the injection of the CM, which usually returns to baseline values over 1-3 weeks. The first 24 hours postexposure are crucial to the development of CI-AKI, since in $80 \%$ of cases serum creatinine started rising within 24 hours post-exposure and nearly all patients who progressed to serious renal dysfunction had an increase in serum creatinine within this period of time. CIAKI is related to serious adverse events, as chronic kidney disease (CKD), myocardial infarction, stroke and death while patients who developed CI-AKI had higher mortality at one month [2,3]. The reported one-year mortality rate varies according to the degree of renal impairment prior to the radiocontrast procedure, ranging from $8-23 \%$, and can be as high as 55\% in those who develop CI-AKI that requires dialysis $[4,5]$. In this review, we present the various methods used in CI-AKI prevention while also elaborating on the novel approaches that are currently being investigated.

\section{Pathophysiology of CI-AKI}

CI-AKI is believed to arise from hypoxic renal medullary injury, leading to acute tubular necrosis, rather than direct toxic renal tubular damage [6,7]. This direct CM-induced renal tubule toxicity leading to apoptosis is due to the inhibition of mitochondrial enzymes activity [7]. Medullary hypoxia results from decreased vasa recta perfusion, increased oxygen consumption from the epithelial tubular cell and altered medullary vasculature reducing the perfusion of the outer renal medulla, which is poor even under normal conditions because of its distance from the descending vasa recta [7]. Osmotic load due to $\mathrm{CM}$ is responsible for increased interstitial pressure and sodium transport by drawing water into the renal tube lumen, resulting in compression of vasa recta and peritubular capillaries and in an increase in blood viscosity, both 
decreasing the perfusion of vasa recta and aggravating medullary hypoxia [8]. Moreover, CM in the lumen of renal tubules decreases water reabsorption, leading to an increase in intraluminal pressure and a decrease in the filtration gradient of glomerular capillaries, enhancing the transport of sodium [9]. The increment of the sodium transport raises the consumption of oxygen by tubular epithelial cells, contributing to CM-related medullary hypoxia [8]. Adenosine, via the $A_{1}$ receptor on afferent arterioles, promotes their constriction, lowering glomerular filtration rate (GFR), delivering less sodium to be reabsorbed, thus contributing to the decrease in oxygen consumption [10]. Exposure to CM induces a medullary vasoconstrictive response, mediated by the release of prostanoids and endothelin from endothelial cells through the activation of the receptor 1 and 3 of prostaglandin $E_{2}$ and of the receptor A of endothelin [11]. The vasoconstricting effect of endothelin is exaggerated in patients with CKD. Medullary hypoxia and catabolism of adenosine also generate reactive oxygen species (ROS) that scavenge nitric oxide (NO) leading to attenuated vasodilation. Additionally, decreased NO increases sodium reabsorption which induces a rise in oxygen consumption and medullary hypoxia.

\section{Prevention for CI-AKI}

\section{CI-AKI Risk Stratification}

Mehran et al. developed a simple risk score for the prediction of CI-AKI and the need for dialysis after PCI by investigating 8357 patients [12]. A weighted integer score is attributed to each risk factor and the sum gives rise to the CI-AKI risk score, a predictor of the risk of CI-AKI occurrence and necessity for dialysis (Table 1). Lately, there has been novel predictors for CI-AKI risk especially in patients undergoing PCI after ST-elevation MI such as the Athens CI-AKI Score or the PRECISE-DAPT $[13,14]$. However, since renal function is a major determinant of CI-AKI incidence, estimation of GFR is usually the most practical method of risk stratification [15] in the elderly, diabetic or hypertensive patient population as well as patients with pre-existing renal disease (Figure 1) [16].

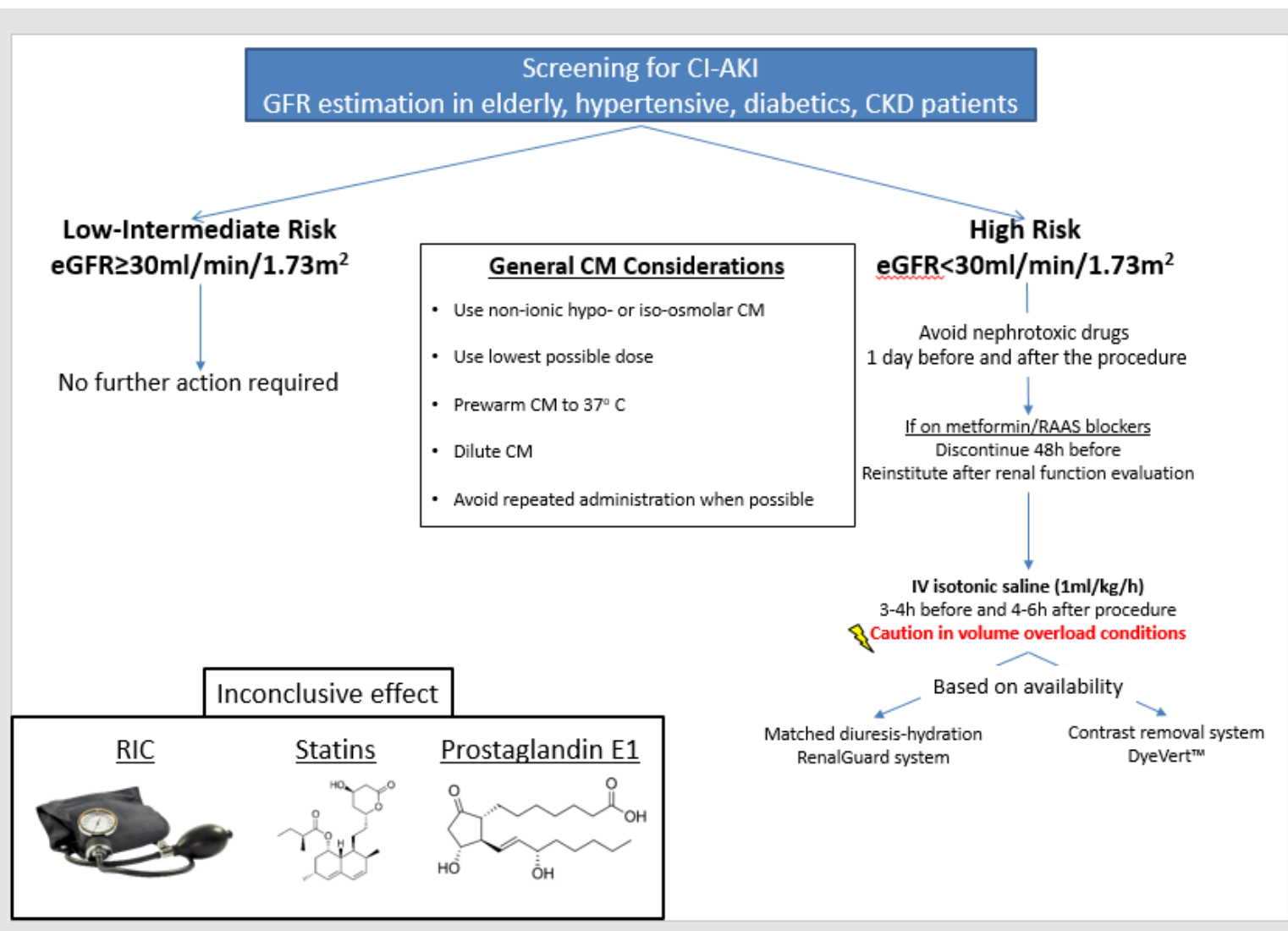

Figure 1: CI-AKI risk stratification.

Table 1: CI-AKI risk factor scores for patients undergoing PCI.

\begin{tabular}{|c|c|}
\hline Risk Factors & Integer Score \\
\hline Hypotension & 5 \\
\hline IABP & 5 \\
\hline CHF & 5 \\
\hline
\end{tabular}




\begin{tabular}{|c|c|c|}
\hline \multicolumn{2}{|c|}{ Age $>75$ years } & 4 \\
\hline \multicolumn{2}{|c|}{ Anemia } & 3 \\
\hline \multicolumn{2}{|c|}{ Diabetes mellitus } & 3 \\
\hline \multicolumn{2}{|c|}{ Contrast media volume (per $100 \mathrm{ml}$ ) } & 1 \\
\hline \multicolumn{2}{|c|}{$\begin{array}{l}\text { Serum creatinine }>1,5 \mathrm{mg} / \mathrm{dl} \\
\text { or }\end{array}$} & 4 \\
\hline \multicolumn{2}{|c|}{ eGFR $40-60 \mathrm{~mL} / \mathrm{min} / 1,73 \mathrm{~m}^{2}$} & 2 \\
\hline \multicolumn{2}{|c|}{ eGFR $20-40 \mathrm{~mL} / \mathrm{min} / 1,73 \mathrm{~m}^{2}$} & 4 \\
\hline \multicolumn{2}{|c|}{$\mathrm{eGFR}<20 \mathrm{~mL} / \mathrm{min} / 1,73 \mathrm{~m}^{2}$} & 6 \\
\hline CI-AKI Risk Score & Risk of CI-AKI (\%) & Risk of Dialysis (\%) \\
\hline $0-5$ & 7,5 & 0,04 \\
\hline $6-10$ & 14,0 & 0,12 \\
\hline $11-16$ & 26,1 & 1,09 \\
\hline$\geq 16$ & 57,3 & 12,6 \\
\hline \multicolumn{3}{|c|}{$\begin{array}{l}\text { CI-AKI: contrast-induced acute kidney injury; CHF: Congestive Heart Failure; eGFR: estimated glomerular filtration rate; } \\
\text { IABP: Intra-aortic balloon pump }\end{array}$} \\
\hline
\end{tabular}

\section{Considerations}

As far as CM is concerned, the use of non-ionic hypo-osmolar or iso-osmolar CM in the lowest possible dose is indicated in patients at particularly high risk, such as patients with diabetes mellitus and advanced CKD [17]. Additionally, the CM should be prewarmed to $37 \mathrm{oC}$ and diluted to decrease viscosity and its administration should be postponed in patients with circulatory collapse or severe CHF until their hemodynamic status is corrected $[17,18]$. Repeated administration of CM should be delayed for 48 hours in patients without risk factors for CI-AKI, for 72 hours in those with risk factors for CI-AKI and, if acute renal impairment develops after CM administration, repeated doses should be delayed until the serum creatinine level has returned to baseline [17]. When the procedure can be delayed, the time frame of 2-3 weeks is appropriate to allow for restoration of renal function [19].

\section{Discontinuation of Nephrotoxic Drugs}

Concurrent nephrotoxic drugs should be withheld, especially NSAIDs, aminoglycosides, amphotericin-B, high doses of loop diuretics and antivirals, at least 24 hours before and after the procedure. The procedure must be delayed long enough to avoid the combined effect of nephrotoxic drugs and the CM, but this is not always possible in cases of emergent procedures [17]. In addition, metformin should be discontinued 48 hours before the procedure and reinstituted after evaluation of renal function in diabetic patients with impaired renal function. Metformin is not a risk factor for CI-AKI, but it could lead to lactic acidosis in case of CI-AKI incidence, as it is excreted via the kidney and stimulates intestinal lactic acid production [20]. Controversy exists in the discontinuation of renin-angiotensin system blocking drugs. For patients treated with angiotensin converting enzyme (ACE) inhibitors or angiotensin receptor blockers (ARBs) receiving CM, some investigators conclude that there is no need to interrupt them prior to CM exposure [21]. On the other hand, the CAPTAIN study of 208 patients reported that CI-AKI occurred in $18.4 \%$ of patients who continued the ACE inhibitor or ARB compared to $10.9 \%$ of the patients who withheld them [22]. In the largest meta-analysis to date, an increased risk of CI-AKI was noted in chronic ACE inhibitors/ARBs users, especially in the subgroup of elderly and patients with CKD [23]. Due to the lack of beneficial results, holding ACE inhibitors or ARBs should be considered especially in these subgroups for 48 hours before and reinstitution after evaluation for CI-AKI [16].

\section{Ischemic Conditioning}

Remote Ischemic Conditioning (RIC), aiming at limiting ischemia-reperfusion injury via protective signals elicited from the tissue in which the conditioning stimulus is applied, was initially proven efficacious by Walsh et al. in a study of 40 patients undergoing endovascular aortic aneurysm repair (EVAR) [24]. Following that, RCTs from Er et al. and Deftereos et al. established the beneficial effect of RIC, either that being pre- or post-ischemic $[25,26]$. Recently, a meta-analysis of 16 RCTs (2157 patients receiving IV CM) showed that RIC markedly decreased the risk of CI-AKI and major adverse cardiovascular events within 6 months while hydration acted synergistically [27]. Several trials are currently underway, and the results are expected to provide further evidence on the efficacy of this approach.

\section{Pharmacological Strategies}

Hydration: Periprocedural hydration has been widely regarded to be the cornerstone of CI-AKI prevention in patients with and without renal impairment $[28,29]$. The beneficial effect of hydration was firstly described by Solomon et al. in a study of 78 patients with CKD undergoing angiography [30]. The mechanism involved includes the inhibition of renin-angiotensin-aldosterone system due to volume expansion, thus attenuating renal vasoconstriction 
and hypoperfusion, together with an increase of vasodilatory renal prostaglandins, leading to extensive vasodilation. Moreover, dilution of intratubular CM and increase of diuresis limits the contact of CM with the renal tubular cells, thus contributing to the reduction of the direct renal tubular toxicity [31]. There is no clear evidence on the best route of hydration, enteral or parenteral, to prevent CIAKI. A meta-analysis of 8 studies with 1754 participants showed noninferiority of oral hydration compared to IV for the prevention of CI-AKI in coronary angiography [32]. Mueller et al. conducted a study with 1620 patients undergoing coronary angiography and concluded that for CI-AKI prophylaxis hydration with isotonic saline 0.9\% (809 patients, incidence of CI-AKI 0.7\%) was more beneficial than half-isotonic saline $0.45 \%$ (811 patients, incidence of CI-AKI $2 \%$ ), especially in women, diabetics and patients receiving equal or greater than $250 \mathrm{~mL}$ of CM [33]. Routine clinical practices generally consist of IV isotonic saline administration at a rate of $1 \mathrm{~mL} / \mathrm{kg} / \mathrm{h}$ 3-4 hours before and 4-6 hours after the procedure [34].

Recently, the breakthrough AMACING trial brought more controversy to the table, as no intervention was non-inferior to IV infusion of $0.9 \%$ saline according to current guidelines for CIAKI prevention, while also being more cost-effective, in patients with eGFR between 30-59 $\mathrm{ml} / \mathrm{min} / 1,73 \mathrm{~m} 2$ referred for elective procedures requiring CM. Importantly, no subgroup differences were noted according to eGFR, diabetes mellitus status or the type of the procedure. Concerning adverse events, $5.5 \%$ of patients receiving IV hydration faced hydration-related complications (namely symptomatic heart failure), providing the rationale for cautious administration of hydration [35]. According to the longterm results of the trial, no differences were observed in survival or in serum creatinine level at one year [36]. The CINART study evaluated the stricter hydration protocol according to the abovementioned results, observing a reduced hospital (hospitalization for prophylaxis, cost) and patient burden (hydration-related complications). In light of this new evidence, prophylactic hydration should be administered only in patients with eGFR $<30$ $\mathrm{ml} / \mathrm{min} / 1.73 \mathrm{~m}^{2}$ [37].

Methods including the assessment of intravascular volume prior to IV hydration, either left ventricular end diastolic pressure (LVEDP)-guided or Central Venous Pressure-guided hydration, have shown promising results in CI-AKI risk reduction of patients with CKD or heart failure [38-41]. However, a recent RCT of 114 patients undergoing coronary angiography failed to demonstrate a benefit of LVEDP-guided hydration protocol over routine hydration on CIAKI [42]. A balanced hydration therapy consisting of temporary forced diuresis with furosemide and replacement of urine output by saline infusion, matched minute-to-minute to urine volume, using the specialized RenalGuard System has also been described (Table 2). Dorval et al. in a study of 23 patients at high risk for CI-AKI development who underwent a radiocontrast procedure, used RenalGuard balanced hydration and noticed CI-AKI incidence lower than predicted (9,5\% versus $14,5 \%$ to $55 \%$ ) [43]. Moreover, in patients undergoing transcatheter aortic valve implantation hydration with RenalGuard was highly protective against CI-AKI (RenalGuard: 1/22 vs. Control: 10/26) [44]. Recently, Briguori et al. highlighted the superiority of RenalGuard system with a urine rate of over $300 \mathrm{ml} /$ hour compared to a LVEDP-guided hydration regimen, as demonstrated by a statistically significant decrease in CI-AKI incidence as well as reduced 1-month major adverse events (death, dialysis-dependent renal failure, pulmonary edema or sustained kidney injury) in patients undergoing coronary and peripheral vessel procedures [45]. Patients on RenalGuard exhibited a higher hypokalemia rate, however. The encouraging results of RenalGuard in such study population will be further evaluated in another RCT of 326 patients at increased risk for CI-AKI (NCT01456013).

Table 2: Studies evaluating the use of RenalGuard for the prevention of CI-AKI in patients at risk.

\begin{tabular}{|c|c|c|c|c|}
\hline Studies & Patients & Study Design & Preventive Strategy & Benefit \\
\hline Briguori et al. [54] & 702 & RCT & $\begin{array}{l}\text { 1. Renal Guard } \\
\text { 2. LVEDP-guided hydration }\end{array}$ & Less CI-AKI, PE and 1-month MAE \\
\hline Katoh et al. [51] & 60 (Japanese) & Observational & 1. Renal Guard & High UFR associated with less CI-AKI \\
\hline Chorin et al. [115] & 300 & Observational & $\begin{array}{l}\text { 1. Renal Guard } \\
\text { 2. Isotonic saline }\end{array}$ & Net decrease in eGFR and CI-AKI incidence \\
\hline Visconti et al. [52] & 48 & Non-randomized & $\begin{array}{l}\text { 1. Renal Guard } \\
\text { 2. SB } \\
\end{array}$ & Protective against CI-AKI (OR 0.71) \\
\hline Briguori et al. [116] & 400 & Observational & 1.Renal Guard & Effective in reaching the target UFR $(\geq 450 \mathrm{ml} / \mathrm{h})$ \\
\hline Barbanti et al. [117] & 112 & RCT & $\begin{array}{l}\text { 1. Renal Guard } \\
\text { 2. Isotonic saline }\end{array}$ & Reduced incidence of CI-AKI \\
\hline Briguori et al. [118] & 292 & RCT & $\begin{array}{l}\text { 1. Renal Guard }(\mathrm{NAC}+\mathrm{SB}) \\
\text { 2. } \mathrm{NAC}+\mathrm{SB}\end{array}$ & Lower CI-AKI and in-hospital dialysis incidence \\
\hline
\end{tabular}

CI-AKI: Contrast-induced acute kidney injury; LVEDP: left ventricular end diastolic pressure; PE: pulmonary edema; MAE: major adverse events; UFR: urinary flow rate; eGFR: estimated glomerular filtration rate; SB: sodium bicarbonate; OR: odds ratio; NAC: N-acetyl Cysteine 
Sodium Bicarbonate: Bicarbonate decreases the acidification of renal tubular fluid, reduces the $\mathrm{pH}$-dependent production of ROS and increases the neutralization of ROS. A meta-analysis of Jang et al. (19 trials, 3609 patients) compared the preventive effect of saline against CI-AKI versus sodium bicarbonate and reported beneficial results from sodium bicarbonate administration without a significant difference in the requirement of dialysis and mortality, but with noticeable changes in serum bicarbonate and potassium levels as a side effect [46]. However, a meta-analysis of 14 unpublished RCT by Zoungas et al. demonstrates that the efficacy of sodium bicarbonate and sodium chloride was not significantly different [47]. More insight was provided by the PRESERVE trial in 5177 high-risk patients undergoing angiography. No beneficial effect of sodium bicarbonate versus IV saline on CI-AKI prevention, need for dialysis or hard end-points, such as death, was observed [48] and in light of this new evidence, their prophylactic administration is not recommended.

$\mathrm{N}$-acetylcysteine: $\mathrm{N}$-acetylcysteine (NAC) has antioxidant and vasodilatory effects. It scavenges ROS, increases the expression of NO synthase, competes with superoxide radicals for NO, combines with NO to form S-nitrosothiol having vasodilatory effects, blocks the expression of vascular cell adhesion molecule-1 (VCAM-1) in glomerular mesangial cells responsible for the recruitment of inflammatory cells and, finally, assists the synthesis of the antioxidant glutathione [49-51]. The protective effect of NAC against CI-AKI is controversial with negative studies being of larger scale than positive, while no study shows a decrease in the need for dialysis in patients who received NAC and developed CI-AKI. Marenzi et al. in a study of 354 patients detected a dose-dependent effect of NAC (CI-AKI risk in the group of $600 \mathrm{mg}$ p.os was reduced by $54.5 \%$ versus $75.8 \%$ in the group of $1200 \mathrm{mg}$ p.os) which has not been confirmed yet [52]. Moreover, Hoffman et al. in a study of 50 healthy individuals who did not receive CM and received NAC, mentioned a drop in serum creatinine and an increase of eGFR, but not of cystatin $\mathrm{C}$ levels and concluded that creatinine metabolism is probably affected from NAC administration and not the renal function [53].

Meta-analysis accessing the effectiveness of NAC against CIAKI was conducted by Selcuk Adabag et al. who reviewed RCTs with oral or IV NAC administration from 1960 until January 2008 (10 RCT, 1163 patients) and saw no impact of NAC against CI-AKI (incidence of CI-AKI in the NAC group 35\% versus 37\% in the control group) [54]. Meta-analysis of Sun et al. from 1966 until September 2012 concerning 10 RCT of 1163 patients with intravenous administration of NAC, demonstrated a positive impact of NAC against CI-AKI occurrence (CI-AKI incidence 7.9\% in the NAC group versus $14.3 \%$ in the control group) [55]. However, based on the most recent data from PRESERVE trial, NAC doesn't affect CI-AKI incidence, the need for dialysis, or death when compared to oral placebo in patients at risk for renal adverse events undergoing angiography [48]. Given all the above date, the use of NAC is not recommended.

Table 3: Studies evaluating the use of statins for the prevention of CI-AKI.

\begin{tabular}{|c|c|c|c|}
\hline Studies & Patients & Preventive Strategy & Benefit \\
\hline Khanal et al. [119] & 29409 & $\begin{array}{l}\text { 1. Long-term statin } \\
\text { 2. No statin }\end{array}$ & Yes \\
\hline Jo et al. [120] & 247 & $\begin{array}{l}\text { 1. Simvastatin } 40 \mathrm{mg} \\
\text { 2. Placebo } \\
\text { All received periprocedural hydration }\end{array}$ & No \\
\hline Patti et al. [121] & 434 & $\begin{array}{l}\text { 1. Long-term statin } \\
\text { 2. No statin } \\
\text { Hydration in patients with } \mathrm{CrCl}<70 \mathrm{ml} / \mathrm{min}\end{array}$ & Yes (except from $\mathrm{CrCL}<40 \mathrm{ml} / \mathrm{min}$ ) \\
\hline Zhao et al. [122] & 279 & $\begin{array}{l}\text { 1. Long-term statin } \\
\text { 2. No statin }\end{array}$ & Yes \\
\hline Xinwei et al. [123] & 228 & $\begin{array}{l}\text { 1. Simvastatin } 20 \mathrm{mg} \\
\text { 2. Simvastatin } 80 \mathrm{mg} \\
\text { All received periprocedural hydration }\end{array}$ & No \\
\hline Kandula et al. [124] & 353 & $\begin{array}{l}\text { 1. Long-term statin } \\
\text { 2. No statin }\end{array}$ & No \\
\hline Patti et al. [125] & 241 & $\begin{array}{l}\text { 1. Atorvastatin } 120 \mathrm{mg} \\
\text { 2. Placebo } \\
\text { Hydration in pts with } \mathrm{CrCl}<60 \mathrm{ml} / \mathrm{min}\end{array}$ & Yes \\
\hline
\end{tabular}




\begin{tabular}{|c|c|c|c|}
\hline Quintavalle et al. [126] & 410 & $\begin{array}{l}\text { 1. Atorvastatin } 80 \mathrm{mg} \\
\text { 2. Control } \\
\text { All received NAC + sodium bicarbonate }\end{array}$ & Yes \\
\hline Han et al. [127] & 2998 & $\begin{array}{l}\text { 1. Rosuvastatin } 10 \mathrm{mg} \\
\text { 2. Standard care }\end{array}$ & Yes \\
\hline Leoncini et al. [128] & 504 & $\begin{array}{l}\text { 1. Rosuvastatin } \\
\text { 2. No statin } \\
\text { All received periprocedural hydration + NAC } \\
2 \mathrm{x} / \text { day from the day before to the day after } \\
\text { angiography. }\end{array}$ & Yes \\
\hline Yoshida et al. [129] & 540 & $\begin{array}{l}\text { 1. Pravastatin } \\
\text { 2. No statin } \\
\text { All received periprocedural hydration }\end{array}$ & Yes \\
\hline Munoz et al. [130] & 261 & $\begin{array}{l}\text { 1. Simvastatin } \\
\text { 2. Pravastatin }\end{array}$ & Less CI-AKI incidence in pravastatin \\
\hline Acikel et al. [131] & 160 & $\begin{array}{l}\text { 1. Atorvastatin } 40 \mathrm{mg} \\
\text { 2. No statin } \\
\text { All received periprocedural hydration }\end{array}$ & Yes \\
\hline Chen et al. [132] & 120 & $\begin{array}{l}\text { 1. Atorvastatin } 20 \mathrm{mg} \\
\text { 2. No statin }\end{array}$ & Yes \\
\hline Abaci et al. [133] & 208 & $\begin{array}{l}\text { 1. Rosuvastatin } 40 \mathrm{mg} \\
\text { 2. No statin } \\
\text { All received periprocedural hydration }\end{array}$ & No \\
\hline Fu et al. [134] & 496 & $\begin{array}{l}\text { 1. Atorvastatin } 10 \mathrm{mg} \\
\text { 2. Atorvastatin } 40 \mathrm{mg} \\
\text { All received periprocedural hydration }\end{array}$ & Yes \\
\hline
\end{tabular}

Statins: Apart from their lipid-lowering properties, statins have anti-oxidative and anti-inflammatory action and they can be renoprotective. They decrease free radical formation through the increase of heme oxygenase-1 protein production, which is an antioxidant protein interfering with NADPH oxidase activity [56]. Studies concerning the effectiveness of statins in CI-AKI prevention had controversial results (Table 3) and, although a benefit was demonstrated in most studies, others have shown minimal, if any, protective effect against CI-AKI. It is worth mentioning that the vast majority of those studies consisted of patients undergoing coronary procedures and, thus, conclusions can mainly be drawn for this specific study population. Meta-analysis of RCTs determining the usefulness of statins against CI-AKI was performed by Zhang BC et al. in 1423 patients pointed that high dose of statins could lower the occurrence of CI-AKI [57]. Another meta-analysis conducted by Zhou et al. on 1009 patients, proved that statins administration was effective only in patients with advanced chronic kidney disease $\left(4^{\text {th }}\right.$ and $5^{\text {th }}$ stage) [58]. Zhang et al. on their meta-analysis of 1194 patients, concluded that the use of statins played an insignificant role in CI-AKI prophylaxis [59]. Furthermore, Liu et al. in a meta- analysis of 9 RCT with 5143 patients (2560 with statin and 2583 as control) found out that patients in the statin group had a $53 \%$ lower risk of CI-AKI compared to the control group and were less likely to require dialysis [60]. Moreover, Liu et al. in their meta-analysis of 9 RCTs detected that atorvastatin administration at high doses before coronary angiography resulted in a noticeable reduction in CI-AKI incidence in comparison to low-dose statin or placebo [61]. Last but not least, Li et al. in their meta-analysis of 21 RCTs (7746 patients undergoing coronary angiography/PCI) confirmed the efficacy of short-term statin administration for the prevention of CI-AKI, despite the heterogenicity of the study group [62].

Despite these encouraging results, there are still unanswered questions regarding the statin of choice, timetable and dosage. However, their use is allowed, particularly in patients undergoing coronary procedures, as it is established that statins were the only preventive approach that was found to significantly and consistently prevent CI-AKI compared to saline by Giacoppo et al. in their Bayesian meta-analysis in the span of two decades (124 trials, 28240 patients, 10 different preventive regiments) [63]. 
Prostaglandins: Prostaglandin E1 (PGE1) and prostacyclin (PGI2) have vasodilatory effects, improving renal blood flow and medullary hypoxia induced by the injected CM. This protective property has been examined by a few studies and, in a recent large meta-analysis of 36 RCTs with 5495 patients receiving CM (alprostadil vs. control), their potential was also demonstrated (Alprostadil: $6.56 \%$ vs. Control: 16.74\%) [64]. In spite of these promising results, they are currently not recommended in CI-AKI prophylaxis and further investigation with larger multicentre RCTs is mandatory.

\section{Contrast Removal Strategies}

Hemodialysis-Hemofiltration: CM can be removed from the blood by intermittent hemodialysis immediately after radiographic contrast studies. A session of hemodialysis can remove $60 \%-90 \%$ of the administered CM. Peritoneal dialysis is also effective in removing the CM but lasts longer than hemodialysis [65]. Several RCTs have assessed the possible protective effect of hemodialysis on CI-AKI prophylaxis, but the majority of them failed to demonstrate a reduced incidence of CI-AKI [66-70]. The reasons why hemodialysis was not beneficial are not known, with the rapid onset of renal injury after the administration of CM or the hemodialysis' nephrotoxicity being possible etiologies [66]. Marenzi et al. in a RCT including 114 patients who underwent coronary interventions proved the efficacy of hemofiltration compared to hydration with isotonic saline [71]. Nevertheless, Schindler et al. in a RCT of 39 patients, compared the removal of CM through hemodialysis with this through hemofiltration and concluded that hemodialysis removed the $\mathrm{CM}$ more effectively than hemofiltration [72]. A recent pilot study of Oyamada et al. showcased the beneficial effect of high-flow intermittent hemodiafiltration during and after coronary or peripheral catheterization procedures compared to saline in a high-risk population, with no events of CI-AKI and a slower 1-year progression of kidney disease being noted [73]. Hemofiltration may, therefore, decrease the risk of CI-AKI, but it is costly, often requires intensive care unit admission and carries its own risks. Therefore, additional studies are needed to support the benefit and cost-effectiveness of hemofiltration.

Contrast Removal-Reduction Systems: During coronary angiography, the removal of the majority of injected CM from the coronary sinuses before it enters the systemic circulation represents an innovative approach. A catheter is inserted into the coronary sinus through the right femoral vein and blood is transferred into an extracorporeal contrast-absorbing column. Even though it has been effective in reducing CI-AKI incidence, a high technique failure rate (57\%) has limited its clinical use [72,74]. More recently, a novel contrast reduction system (DyeVert ${ }^{\mathrm{TM}}$ ) was employed for the prevention of CI-AKI, based on limiting excess CM administration and aortic reflux. Its impact was evaluated in 96 patients undergoing coronary angiography, with results showing less CM exposure without affecting image quality [75]. This CM volume reduction translated in a lower incidence of CIAKI in a study of 451 patients undergoing coronary procedures for acute coronary syndromes (DyeVert ${ }^{\mathrm{TM}}$ : 8\% vs. Control: 19\%) [76]. Importantly, in a UK-based cost-utility analysis, the use of DyeVert ${ }^{\mathrm{TM}}$ was accompanied with a significant cost savings as well as improve quality of life effectiveness [77].

\section{Conclusion}

Prevention is the cornerstone of CI-AKI management starting with risk assessment, application of CM-related measures and withholding nephrotoxic drugs. Saline hydration, once considered a routine clinical practice, should only be reserved for patients at high risk for CI-AKI. The efficacy of the mentioned pharmacological agents is controversial was mostly reported in small trials, with statins emerging as the most effective drug in CI-AKI prevention in cases of coronary procedures. Ischemic conditioning, RenalGuard balanced hydration and contrast manipulation systems trials provided some encouraging results but their use is not widely adopted in routine clinical practice.

\section{Acknowledgments}

None.

\section{Funding}

No funding received.

\section{Conflict of Interest}

The authors declare that they have no conflict of interest.

\section{References}

1. Nash K, A Hafeez, S Hou (2002) Hospital-acquired renal insufficiency. Am J Kidney Dis 39(5): 930-936.

2. Solomon RJ (2009) Contrast-induced nephropathy and long-term adverse events: cause and effect? Clin J Am Soc Nephrol 4(7): 1162-1169.

3. Chong E, Poh KK, Liang S, Tan HC (2010) Risk factors and clinical outcomes for contrast-induced nephropathy after percutaneous coronary intervention in patients with normal serum creatinine. Ann Acad Med Singapore 39(5): 374-380.

4. Dangas G, Ioannis I, E Nikolsky, Eve DA, Gary SM, et al. (2005) Contrastinduced nephropathy after percutaneous coronary interventions in relation to chronic kidney disease and hemodynamic variables. Am J Cardiol 95(1): 13-19.

5. Gruberg L, Gary S Mintz, Roxana Mehran, George Dangas, Alexandra J Lansky, et al. (2000) The prognostic implications of further renal function deterioration within $48 \mathrm{~h}$ of interventional coronary procedures in patients with pre-existent chronic renal insufficiency. J Am Coll Cardiol 36(5): 1542-1548.

6. Heyman SN, S Rosen, C Rosenberger (2008) Renal parenchymal hypoxia, hypoxia adaptation, and the pathogenesis of radiocontrast nephropathy. Clin J Am Soc Nephrol 3(1): 288-296.

7. Wong PC (2012) Pathophysiology of contrast-induced nephropathy. Int J Cardiol 158(2): 186-192. 
8. Ueda J, A Nygren, P Hansell (1993) Effect of intravenous contrast media on proximal and distal tubular hydrostatic pressure in the rat kidney. Acta Radiol 34(1): 83-87.

9. Tumlin J (2006) Pathophysiology of contrast-induced nephropathy. Am J Cardiol 98(6A): 14K-20K

10. Vallon V (2003) Tubuloglomerular feedback and the control of glomerular filtration rate. News Physiol Sci 18: 169-174.

11. Cantley LG, K Spokes, B Clark, Ellen GM, J Carter, et al. (1993) Role of endothelin and prostaglandins in radiocontrast-induced renal artery constriction. Kidney Int 44(6): 1217-1223.

12. Mehran R, Eve DA, E Nikolsky, Zoran L, Ioannis I, et al. (2004) A simple risk score for prediction of contrast-induced nephropathy after percutaneous coronary intervention: development and initial validation. J Am Coll Cardiol 44(7): 1393-1399.

13. Cinar T, Veysel Ozan Tanık, Emre Aruğaslan, Yavuz Karabağ, Metin Çağdaş, et al. (2018) The association of PRECISE-DAPT score with development of contrast-induced nephropathy in patients with STelevation myocardial infarction undergoing primary percutaneous coronary intervention. Cardiovasc Interv Ther 34: 207-215.

14. Lazaros G, Theodoros Zografos, Evangelos Oikonomou, G Siasos, Georgios Georgiopoulos, et al. (2016) Usefulness of C-Reactive Protein as a Predictor of Contrast-Induced Nephropathy After Percutaneous Coronary Interventions in Patients with Acute Myocardial Infarction and Presentation of a New Risk Score (Athens CIN Score). Am J Cardiol 118(9): 1329-1333.

15. Davenport MS (2013) Contrast medium-induced nephrotoxicity risk assessment in adult inpatients: a comparison of serum creatinine leveland estimated glomerular filtration rate-based screening methods. Radiology 269(1): 92-100.

16. Davenport MS, Mark A Perazella, Jerry Yee, Jonathan R Dillman, Derek Fine, et al. (2020) Use of Intravenous Iodinated Contrast Media in Patients with Kidney Disease: Consensus Statements from the American College of Radiology and the National Kidney Foundation. Radiology 294(3): 660-668.

17. Liss P, Anders Nygren, Uno Erikson, Hans R Ulfendahl (1998) Injection of low and iso-osmolar contrast medium decreases oxygen tension in the renal medulla. Kidney Int 53(3): 698-702.

18. Fader MI (1986) Preheated contrast media: the advantage of intravenous injection. Radiol Technol 58(2): 117-119.

19. Marenzi G, Emilio A, Jeness C, G Lauri, Ivana M, et al. (2009) Contrast volume during primary percutaneous coronary intervention and subsequent contrast-induced nephropathy and mortality. Ann Intern Med 150(3): 170-177.

20. McCullough PA (2008) Contrast-induced acute kidney injury. J Am Coll Cardiol 51(15): 1419-1428.

21. Rosenstock JL, Robert B, JK Kim (2008) The effect of withdrawal of ACE inhibitors or angiotensin receptor blockers prior to coronary angiography on the incidence of contrast-induced nephropathy. Int Urol Nephrol 40(3): 749-755.

22. Bainey KR, S Rahim, Krystal E, ML Rokoss (2015) Effects of withdrawing vs continuing renin-angiotensin blockers on incidence of acute kidney injury in patients with renal insufficiency undergoing cardiac catheterization: Results from the Angiotensin Converting Enzyme Inhibitor/Angiotensin Receptor Blocker and Contrast Induced Nephropathy in Patients Receiving Cardiac Catheterization (CAPTAIN) trial. Am Heart J 170(1): 110-116.

23. Jo SH (2015) The impact of renin-angiotensin-aldosterone system blockade on contrast-induced nephropathy: a meta-analysis of 12 studies with 4,493 patients. Cardiology 130(1): 4-14.
24. Walsh SR (2009) Remote ischemic preconditioning for renal and cardiac protection during endovascular aneurysm repair: a randomized controlled trial. J Endovasc Ther 16(6): 680-689.

25. Deftereos S, Georgios G (2013) Renoprotective effect of remote ischemic post-conditioning by intermittent balloon inflations in patients undergoing percutaneous coronary intervention. J Am Coll Cardiol 61(19): 1949-1955.

26. Er F (2012) Ischemic preconditioning for prevention of contrast medium-induced nephropathy: randomized pilot RenPro Trial (Renal Protection Trial). Circulation 126(3): 296-303.

27.Zhou CC, Wen TY, YZ Ge (2017) Remote ischemic conditioning for the prevention of contrast-induced acute kidney injury in patients undergoing intravascular contrast administration: a meta-analysis and trial sequential analysis of 16 randomized controlled trials. Oncotarget 8(45): 79323-79336.

28. Levine GN, Eric RB, James CB, Steven RB, John AB, et al, (2011) ACCF/ AHA/SCAI Guideline for Percutaneous Coronary Intervention: a report of the American College of Cardiology Foundation/American Heart Association Task Force on Practice Guidelines and the Society for Cardiovascular Angiography and Interventions. Circulation 124(23): e574-651.

29. Kolh P, S Windecker (2014) ESC/EACTS myocardial revascularization guidelines 2014. Eur Heart J 35(46): 3235-3236.

30. Solomon R, Werner C, Mann D (1994) Effects of saline, mannitol, and furosemide on acute decreases in renal function induced by radiocontrast agents. N Engl J Med 331(21): 1416-1420.

31. Weisbord SD, PM Palevsky (2008) Prevention of contrast-induced nephropathy with volume expansion. Clin J Am Soc Nephrol 3(1): 273280.

32.Zhang W (2008) Effectiveness of oral hydration in preventing contrast-induced acute kidney injury in patients undergoing coronary angiography or intervention: a pairwise and network meta-analysis. Coron Artery Dis.

33. Mueller C (2002) Prevention of contrast media-associated nephropathy: randomized comparison of 2 hydration regimens in 1620 patients undergoing coronary angioplasty. Arch Intern Med 162(3): 329-336.

34. Van der Molen AJ, P Reimer, IA Dekkers, Georg B (2018) Post-contrast acute kidney injury. Part 2: risk stratification, role of hydration and other prophylactic measures, patients taking metformin and chronic dialysis patients: Recommendations for updated ESUR Contrast Medium Safety Committee guidelines. Eur Radiol 28(7): 2856-2869.

35. Nijssen EC, Patty JN, Roger JR, VV Ommen, JE Wildbreger, et al. (2017) Prophylactic hydration to protect renal function from intravascular iodinated contrast material in patients at high risk of contrastinduced nephropathy (AMACING): a prospective, randomised, phase 3, controlled, open-label, non-inferiority trial. Lancet 389(10076): 13121322.

36. Nijssen EC, Patty JN, Roger JR, VV Ommen (2018) Prophylactic Intravenous Hydration to Protect Renal Function From Intravascular Iodinated Contrast Material (AMACING): Long-term Results of a Prospective, Randomised, Controlled Trial. E Clinical Medicine (4-5): 109-116.

37. Nijssen EC (2020) Impact on clinical practice of updated guidelines on iodinated contrast material: CINART. Eur Radiol.

38. Bader BD (2004) What is the best hydration regimen to prevent contrast media-induced nephrotoxicity? Clin Nephrol 62(1): 1-7.

39. Brar SS, Vicken A, Prakash M, Naing M, AYJ Shen, et al. (2014) Haemodynamic-guided fluid administration for the prevention of contrast-induced acute kidney injury: the POSEIDON randomised controlled trial. Lancet 383(9931): 1814-1823. 
40. Krasuski RA (2003) Optimal timing of hydration to erase contrastassociated nephropathy: the OTHER CAN study. J Invasive Cardiol 15(12): 699-702.

41. Qian G, Z Fu, Jun G, F Cao, Y chen, et al. (2016) Prevention of ContrastInduced Nephropathy by Central Venous Pressure-Guided Fluid Administration in Chronic Kidney Disease and Congestive Heart Failure Patients. JACC Cardiovasc Interv 9(1): 89-96.

42. Marashizadeh A (2019) Left ventricular end-diastolic pressure-guided hydration for the prevention of contrast-induced acute kidney injury in patients with stable ischemic heart disease: the LAKESIDE trial. Int Urol Nephrol 51(10): 1815-1822.

43. Dorval JF, Simon RD, RB Zelman (2013) Feasibility study of the RenalGuard balanced hydration system: a novel strategy for the prevention of contrast-induced nephropathy in high risk patients. Int J Cardiol 166(2): 482-486.

44. Visconti G, Carmen DA, FD Micco (2016) RenalGuard System for the prevention of acute kidney injury in patients undergoing transcatheter aortic valve implantation. EuroIntervention 11(14): e1658-e1661.

45. Briguori C (2020) Left Ventricular End-Diastolic Pressure Versus Urine Flow Rate-Guided Hydration in Preventing Contrast-Associated Acute Kidney Injury. JACC Cardiovasc Interv 13(17): 2065-2074.

46. Jang JS (2012) Sodium bicarbonate therapy for the prevention of contrast-induced acute kidney injury - a systematic review and metaanalysis. Circ J 76(9): 2255-2265.

47. Zoungas S, Toshiharu Ninomiya, Rachel Huxley, Alan Cass, Meg Jardine, et al. (2009) Systematic review: sodium bicarbonate treatment regimens for the prevention of contrast-induced nephropathy. Ann Intern Med 151(9): 631-638.

48. Weisbord SD (2018) Outcomes after Angiography with Sodium Bicarbonate and Acetylcysteine. N Engl J Med 378(7): 603-614.

49. Khachigian LM, T Collins, JW Fries (1997) N-acetyl cysteine blocks mesangial VCAM-1 and NF-kappa B expression in vivo. Am J Pathol 151(5): 1225-1229.

50. Lopez BL (1998) N-acetylcysteine enhances endothelium-dependent vasorelaxation in the isolated rat mesenteric artery. Ann Emerg Med 32(4): 405-410.

51. Safirstein R, L Andrade, JM Vieira (2000) Acetylcysteine and nephrotoxic effects of radiographic contrast agents--a new use for an old drug. N Engl J Med 343(3): 210-212.

52. Marenzi G, Emilio A, Ivana M, G Lauri, Jeness C, et al. (2006) $\mathrm{N}$-acetylcysteine and contrast-induced nephropathy in primary angioplasty. N Engl J Med 354(26): 2773-2782.

53. Hoffmann U, Michael F, B Kruger, Wolfgang D, BK Kramer, et al. (2004) The value of $\mathrm{N}$-acetylcysteine in the prevention of radiocontrast agentinduced nephropathy seems questionable. J Am Soc Nephrol 15(2): 407410.

54. Adabag AS, Areef Ishani, Hanna E Bloomfield, Anita K Ngo, Timothy J Wilt, et al. (2009) Efficacy of $\mathrm{N}$-acetylcysteine in preventing renal injury after heart surgery: a systematic review of randomized trials. Eur Heart J 30(15): 1910-1917.

55. Sun Z (2013) Intravenous $\mathrm{N}$-acetylcysteine for prevention of contrastinduced nephropathy: a meta-analysis of randomized, controlled trials. PLoS One 8(1): e55124.

56. Stoll LL (2004) Antioxidant effects of statins. Drugs Today (Barc) 40(12): 975-990.

57. Zhang BC, WM Li, YW Xu (2011) High-dose statin pretreatment for the prevention of contrast-induced nephropathy: a meta-analysis. Can J Cardiol 27(6): 851-858.
58. Zhou Y (2011) Short-term, high-dose statins in the prevention of contrast-induced nephropathy: a systematic review and meta-analysis. Clin Nephrol 76(6): 475-483.

59.Zhang T (2011) Statins for the prevention of contrast-induced nephropathy: a systematic review and meta-analysis. Am J Nephrol 33(4): 344-351.

60. Liu YH, Y Liu, CY Duan, N Tan, JY Chen, et al. (2015) Statins for the Prevention of Contrast-Induced Nephropathy After Coronary Angiography/Percutaneous Interventions: A Meta-analysis of Randomized Controlled Trials. J Cardiovasc Pharmacol Ther 20(2): 181192.

61. Liu LY (2018) Efficacy of atorvastatin on the prevention of contrastinduced acute kidney injury: a meta-analysis. Drug Des Devel Ther 12 : 437-444.

62. Li H, C Wang, C Liu, R Li, M Zou, et al. (2016) Efficacy of Short-Term Statin Treatment for the Prevention of Contrast-Induced Acute Kidney Injury in Patients Undergoing Coronary Angiography/Percutaneous Coronary Intervention: A Meta-Analysis of 21 Randomized Controlled Trials. Am J Cardiovasc Drugs 16(3): 201-219.

63. Giacoppo D, Giuseppe Gargiulo, Sergio Buccheri, Patrizia Aruta, Robert A Byrne, et al. (2017) Preventive Strategies for Contrast-Induced Acute Kidney Injury in Patients Undergoing Percutaneous Coronary Procedures: Evidence from a Hierarchical Bayesian Network MetaAnalysis of 124 Trials and 28240 Patients. Circ Cardiovasc Interv 10(5).

64. Xie J, M Jiang, Y Lin, H Deng, Lang L (2019) Effect of Alprostadil on the Prevention of Contrast-Induced Nephropathy: A Meta-Analysis of 36 Randomized Controlled Trials. Angiology 70(7): 594-612.

65. Deray G (2006) Dialysis and iodinated contrast media. Kidney Int Suppl (100): S25-S29.

66. Vogt B (2001) Prophylactic hemodialysis after radiocontrast media in patients with renal insufficiency is potentially harmful. Am J Med 111(9): 692-698.

67. Lehnert $\mathrm{T}$ (1998) Effect of haemodialysis after contrast medium administration in patients with renal insufficiency. Nephrol Dial Transplant 13(2): 358-362.

68. Reinecke H (2007) A randomized controlled trial comparing hydration therapy to additional hemodialysis or $\mathrm{N}$-acetylcysteine for the prevention of contrast medium-induced nephropathy: the Dialysis-versus-Diuresis (DVD) Trial. Clin Res Cardiol 96(3): 130-139.

69. Kawashima S (2006) Prophylactic hemodialysis does not prevent contrast-induced nephropathy after cardiac catheterization in patients with chronic renal insufficiency. Circ J 70(5): 553-558.

70. Lee PT, Kang JC, CP Liu, GY Mar, CL Chen, et al. (2007) Renal protection for coronary angiography in advanced renal failure patients by prophylactic hemodialysis. A randomized controlled trial. J Am Coll Cardiol 50(11): 1015-1020.

71. Marenzi G, Ivana M, G Lauri, Emilio A, M Grazi, et al. (2003) The prevention of radiocontrast-agent-induced nephropathy by hemofiltration. $\mathrm{N}$ Engl J Med 349(14): 1333-1340.

72. Schindler R, Carsten Stahl, Stephan Venz, Klaus Ludat, Werner Krause, et al. (2001) Removal of contrast media by different extracorporeal treatments. Nephrol Dial Transplant 16(7): 1471-1474.

73. Oyamada N, Ichiro Hamanaka, Ayumu Fujioka, Toshihiro Iwasaku, Takeya Minami, et al. (2019) Effectiveness of high flow-volume intermittent hemodiafiltration during and after intervention to prevent contrastinduced nephropathy in patients with advanced chronic kidney disease: A pilot study. Catheter Cardiovasc Interv 96(6): 1174-1181.

74. Danenberg HD, Chaim Lotan, Boris Varshitski, Shimon Rosenheck, A Teddy Weiss (2008) Removal of contrast medium from the coronary 
sinus during coronary angiography: feasibility of a simple and available technique for the prevention of nephropathy. Cardiovasc Revasc Med 9(1): 9-13.

75. Desch S (2018) Impact of a novel contrast reduction system on contrast savings in coronary angiography - The DyeVert randomised controlled trial. Int J Cardiol 257: 50-53.

76. Briguori C, Marco Golino, Nicola Porchetta, Mario Scarpelli, Francesca De Micco, et al. (2020) Impact of a contrast media volume control device on acute kidney injury rate in patients with acute coronary syndrome. Catheter Cardiovasc Interv.

77. Javanbakht M, Mohsen Rezaei Hemami, Atefeh Mashayekhi, Michael Branagan-Harris, Azfar G Zaman, et al. (2020) DyeVert PLUS EZ System for Preventing Contrast-Induced Acute Kidney Injury in Patients Undergoing Diagnostic Coronary Angiography and/or Percutaneous Coronary Intervention: A UK-Based Cost-Utility Analysis. Pharmacoecon Open 4(5): 459-472.
ISSN: 2574-1241

DOI: 10.26717/BJSTR.2021.35.005771

Panagiotis Theofilis. Biomed J Sci \& Tech Res

(C) (P) This work is licensed under Creative

Submission Link: https://biomedres.us/submit-manuscript.php

$\begin{array}{ll}\text { BIOMEDICAL } & \text { Assets of Publishing with us } \\ \text { RESEARCHES } & \text { - Global archiving of articles } \\ & \text { - Immediate, unrestricted online access } \\ & \text { - Rigorous Peer Review Process } \\ & \text { - Authors Retain Copyrights }\end{array}$

